\title{
Ability of Dentists and Students to Detect Caries by Using the International Caries Detection and Assessment System
}

\author{
Saleh Al Dhubayb \\ Mohammed Al Sultan \\ Sultan Al Sudairi \\ Fahd Hakami \\ Fahad Saleh AI Sweleh (iD) \\ Dental Clinics, Dental University \\ Hospital, King Saud University, Riyadh, \\ Kingdom of Saudi Arabia
}

\begin{abstract}
Objective: To evaluate the ability of dentists and dental students to detect caries by using the International Caries Detection and Assessment System (ICDAS).

Materials and Methods: A cross-sectional study was conducted in Riyadh city and in the College of Dentistry at King Saud University (KSU) in Saudi Arabia. The study sample included a cluster sampling of 50 private clinics (100 dentists) and all 3rd-, 4th-, and 5th-year students (393 students). Data were collected using an electronic questionnaire. The ability score of detecting caries for each group was identified by calculating the mean percentages of the score. The data were entered into SPSS Version 20. One-way ANOVA was used for comparing quantitative data.

Results: The overall response rate of the survey was $64.5 \%$ (318/493). A total of $62.6 \%$ (199) of respondents know about ICDAS. All groups had difficulty assessing the activity of caries in Code 2. There were significant differences among all groups in the ability to detect caries (P-value: 0:00). Moreover, 4th- and 5th-year students had the highest mean of percentage ability score $(53.8 \%$ and $57.6 \%$, respectively) to detect caries using ICDAS compared to 3rd-year students and general practitioners (38.6\% and $38.7 \%$, respectively).

Conclusion: Overall, detection of early dental caries limited to enamel was confusing and difficult. The abilities of dentists and dental students to detect caries using ICDAS were low and require improvement by continuing further clinical training.
\end{abstract}

Keywords: ICDAS, dental caries, dental student, dentist

\section{Introduction}

Dental caries is defined as "a biofilm-mediated, sugar-driven, multifactorial, dynamic disease that results in the phasic demineralization and remineralization of dental hard tissues". The global prevalence of dental caries of permanent teeth is $35.29,{ }^{2}$ whereas local prevalence in Saudi Arabia is $59-80 \%{ }^{3}$. Many studies have investigated the prevalence of dental caries in Riyadh city. Wyne et al (2002) found that the prevalence was $94.4 \%{ }^{4}$ In another study in 2018 , Alhabdan et al found that the prevalence was $83 \%{ }^{5}$ A recent study in 2019 found that the prevalence was $64.98-85.77 \%{ }^{6}{ }^{6}$

There are many conventional methods to detect dental caries, such as visual inspection, tactile sensation, and radiography. The International Caries Detection and Assessment System (ICDAS) is a clinical scoring system that allows detection and assessment of caries activity. It was established in 2002. It was decided in the convention that there was a need to use a new system for detection of caries because there was a problem with the current system. Later on, in Michigan,
Correspondence: Saleh Al Dhubayb; Fahad Saleh Al Sweleh

Dental Clinics, University Hospital, King

Saud University, Riyadh, Kingdom of Saudi Arabia

Tel +966596600956

Email salehaldhubayb@gmail.com;

fsweleh@yahoo.co.uk 
development of the criteria for the new system, ICDAS criteria (ICDAS I), resulted in 2 groups: caries activity criteria and caries detection criteria. Two more meetings in Indiana in 2003 and in Denmark were held to evaluate these criteria. In 2005, the ICDAS II workshop was conducted to share the progress of ICDAS criteria and input from experts. In total, 60 researches that accepted the criteria of the ICDAS II version and reported that ICDAS research still needs to explore more activities and criteria. $^{7}$

ICDAS has been used and examined by many studies, and it identifies dental caries lesions on the basis of clinical visual appearance. ${ }^{8}$ It consists of seven codes from 0 to 6 , as shown in Table 1 , to detect 6 stages of caries severity. ${ }^{9}$

The ICDAS measures the surface changes and histological depth of carious lesions. Therefore, to apply the ICDAS system, teeth need to be clean and dry during examination. The ICDAS examination is visually aided by a ball-ended explorer, ${ }^{10}$ not a sharp explorer which might damage the enamel surface. ${ }^{11}$

Many studies have reported that ICDAS is useful for detecting caries at different stages, including both cavitated as well as non-cavitated carious lesions. ${ }^{12,13}$ ICDAS simplifies the method of diagnosis, increases its precision and standardization of caries detection to improve patient care, and monitoring the development of caries in research studies. ${ }^{14}$ The ICDAS has $70 \%$ to $85 \%$ sensitivity and a specificity of $80 \%$ to $90 \% .{ }^{15}$ It is flexible to be used in clinical practice, clinical research, and dental education. ${ }^{7,13}$ To the best of the authors' knowledge, no previously published studies made comparisons between general practitioners and students.

The purpose of the current study was to evaluate the ability of dentists and dental students to detect caries by using the ICDAS.

\section{Materials and Methods}

The current cross-sectional study was conducted in Riyadh city and in the College of Dentistry at King Saud University (KSU) in Saudi Arabia. Riyadh city is the capital and the largest city of Saudi Arabia with a population of 6.9 million. The College of Dentistry is the oldest dental college in Saudi Arabia and was established in 1957 as a public college; it graduates approximately 100 students per year and accommodates approximately 595 students at all levels (300 male and 185 female students). It consists of 500 dental clinics for training. In the 3rd-year, dental students start clinical courses after completing preclinical courses at the previous level. They receive information regarding dental disease and treatment. At this level, they examine and treat live patients which is considered the first time performing operative treatments. The 4th- and 5th-year students are exposed to more information and advanced cases in the clinic.

This study included general practitioners in private clinics from five areas in Riyadh city and 3rd-, 4th-, and 5th-year dental students. Exclusion criteria were specialists and consultants in private clinics and non-KSU dental students.

The study sample was a cluster sampling of 50 private dental clinics (100 dentists with bachelor's degree in dentistry) from 5 areas in Riyadh city and all 3rd-, 4th-, and 5th-year students (393 students) of the College of Dentistry at KSU. Ethical approval was received from the Institutional Review Board from the College of Medicine at King Saud University (No E-19-4385). The current study was in accordance with national, international, and institutional guidelines and the Declaration of Helsinki.

The data were collected using an electronic questionnaire, which consisted of demographic data, professional group, and 10 multiple choice questions with eight clinical pictures of different teeth. The clinical pictures were adopted from the ICDAS website ${ }^{16}$ after obtaining approval from the author by e-mail.

A pilot test was conducted by distributing the questionnaire to 3 general practitioners and 5 students who had experience in the clinic and were excluded from the study. Researchers sent electronic questionnaires to all samples through a web link (SurveyMonkey). An introductory first page was attached to the questionnaire explaining the purpose of the study and assuring the confidentiality of the participants' information. Participation was voluntary, and all responses to the questions were anonymous. Respondents did not receive financial or other incentives for participating in the questionnaire. Informed consent was obtained from participants prior to data collection. The datasets used and analyzed during the current study are available from the corresponding author upon reasonable request.

\section{Statistical Analysis}

Data were entered into SPSS Version 20 (IBM, New York, USA). Descriptive statistics (frequency and table) was used to describe the basic features of the data. The ability 
Table I ICDAS Code9

\begin{tabular}{|c|c|c|}
\hline Codes & Pit and Fissures & Smooth Surface \\
\hline $\begin{array}{l}\text { Code } 0 \\
\text { Sound }\end{array}$ & $\begin{array}{l}\text { There should be no evidence of caries Surfaces with } \\
\text { developmental defects such as enamel hypoplasia; fluorosis; } \\
\text { tooth wear and extrinsic or intrinsic stains will be } \\
\text { recorded as sound. }\end{array}$ & $\begin{array}{l}\text { There should be no evidence of caries. Surfaces with } \\
\text { developmental defects such as enamel hypoplasias; } \\
\text { fluorosis; tooth wear and extrinsic or intrinsic stains will } \\
\text { be recorded as sound. }\end{array}$ \\
\hline $\begin{array}{l}\text { Code I } \\
\text { First Visual Change in } \\
\text { Enamel }\end{array}$ & $\begin{array}{l}\text { When seen wet there is no evidence of any change in color } \\
\text { attributable to carious activity, but after prolonged air } \\
\text { drying, a carious opacity or discoloration (white or brown } \\
\text { lesion) is visible, which is not consistent with the clinical } \\
\text { appearance of sound enamel, or when there is a change of } \\
\text { color due to caries it is not consistent with the clinical } \\
\text { appearance of sound enamel and is limited to the confines } \\
\text { of the pit and fissure area (whether seen wet or dry). }\end{array}$ & $\begin{array}{l}\text { When seen wet there is no evidence of any change in color } \\
\text { attributable to carious activity, but after prolonged air } \\
\text { drying a carious opacity (white or brown lesion) is visible } \\
\text { that is not consistent with the clinical appearance of sound } \\
\text { enamel. This will be seen from the buccal or lingual surface. }\end{array}$ \\
\hline $\begin{array}{l}\text { Code } 2 \\
\text { Distinct Visual Change } \\
\text { in Enamel }\end{array}$ & $\begin{array}{l}\text { The tooth must be viewed wet. When wet there is } \\
\text { a carious opacity (white spot lesion)and/or brown carious } \\
\text { discoloration which is wider than the natural fissure/fossa } \\
\text { that is not consistent with the clinical appearance of sound } \\
\text { enamel }\end{array}$ & $\begin{array}{l}\text { There is a carious opacity or discoloration (white or } \\
\text { brown lesion) that is not consistent with the clinical } \\
\text { appearance of sound enamel. This lesion may be seen } \\
\text { directly when viewed from the buccal or lingual direction. } \\
\text { In addition, when viewed from the occlusal direction, this } \\
\text { opacity or discoloration may be seen as a shadow confined } \\
\text { to enamel, seen through the marginal ridge. }\end{array}$ \\
\hline $\begin{array}{l}\text { Code } 3 \\
\text { Localized Enamel } \\
\text { Breakdown }\end{array}$ & $\begin{array}{l}\text { The tooth viewed wet may have a clear carious opacity } \\
\text { (white spot lesion) and/or brown carious discoloration } \\
\text { which is wider than the natural fissure/fossa that is not } \\
\text { consistent with the clinical appearance of sound enamel. } \\
\text { Once dried for approximately } 5 \text { seconds there is carious } \\
\text { loss of tooth structure at the entrance to, or within, the pit } \\
\text { or fissure/fossa. }\end{array}$ & $\begin{array}{l}\text { Once dried for approximately } 5 \text { seconds there is distinct } \\
\text { loss of enamel integrity, viewed from the buccal or lingual } \\
\text { direction. The base and walls of the cavity are within } \\
\text { enamel and dentin is NOT visible. }\end{array}$ \\
\hline $\begin{array}{l}\text { Code } 4 \\
\text { Underlying } \\
\text { Dark Shadow from } \\
\text { Dentin }\end{array}$ & $\begin{array}{l}\text { This lesion appears as a shadow of discolored dentin visible } \\
\text { through an apparently intact enamel surface which may or } \\
\text { may not show signs of localized breakdown (loss of } \\
\text { continuity of the surface that is not showing the dentin). } \\
\text { The shadow appearance is often seen more easily when } \\
\text { the tooth is wet. }\end{array}$ & $\begin{array}{l}\text { This lesion appears as a shadow of discolored dentin } \\
\text { visible through an apparently intact marginal ridge, buccal } \\
\text { or lingual walls of enamel. This appearance is often seen } \\
\text { more easily when the tooth is wet. The darkened area is an } \\
\text { intrinsic shadow which may appear as grey, blue or brown } \\
\text { in color }\end{array}$ \\
\hline $\begin{array}{l}\text { Code } 5 \\
\text { Distinct Cavity with } \\
\text { Visible Dentin }\end{array}$ & $\begin{array}{l}\text { Cavitation in opaque or discolored enamel exposing the } \\
\text { dentin beneath involving less than half of the tooth surface. }\end{array}$ & $\begin{array}{l}\text { Cavitation in opaque or discolored enamel exposing the } \\
\text { dentin beneath involving less than half of the tooth surface }\end{array}$ \\
\hline $\begin{array}{l}\text { Code } 6 \\
\text { Extensive Distinct } \\
\text { Cavity with Visible } \\
\text { Dentin }\end{array}$ & $\begin{array}{l}\text { Cavitation in opaque or discolored enamel exposing the } \\
\text { dentin beneath involving at least half of the tooth surface }\end{array}$ & $\begin{array}{l}\text { Cavitation in opaque or discolored enamel exposing the } \\
\text { dentin beneath involving at least half of the tooth surface }\end{array}$ \\
\hline
\end{tabular}

Notes: Reprinted with permission from Sebastian TS, Johnson T. International caries detection and assessment system (ICDAS): an integrated approach. Int J Oral Heal Med Res. 2015;2(3):81-84. ${ }^{9}$

score of detecting caries for each group was identified by calculating the mean percentages of the score, which is the correct answer of the completed questionnaire. One-way ANOVA was used for comparing quantitative data. A P-value less than 0.05 was considered as the level of significance.

\section{Results}

The overall response rate of the survey was $64.5 \%$ (318/ 493). The percentage of respondents is shown in Table 2. A total of $62.6 \%$ (199) respondents knew about ICDAS, whereas $37.4 \%$ (119) did not know about it. Table 3 shows the percentage of the used system to detect dental caries. 
Table 2 Response Rate of All Respondents

\begin{tabular}{|l|c|}
\hline Respondents & Percentage\%(n) \\
\hline 3rd year undergraduate student & $57.5 \%(77 / / 34)$ \\
4th year undergraduate student & $52.3 \%(69 / / 32)$ \\
5th year undergraduate student & $56.7 \%(72 / 127)$ \\
General practitioner & $100 \%(100 / 100)$ \\
Total & $64.5 \%(3 / 8 / 493)$ \\
\hline
\end{tabular}

Approximately 52.5\% (167) did not use any caries detection system.

Table 4 explains the recognition of all groups to dental caries and selecting of the correct code for each stage of caries in addition to selecting a proper treatment plan. It shows that all groups had difficulty assessing the activity of caries in Code 2. Most of the 3rd-year students and general practitioners recognized the presence of dental caries, but they could not select the proper ICDAS code. Moreover, they knew the proper treatment plan for moderate and advance dental caries. They also suggested follow-up is the option treatment plan for initial dental caries.

Most of the 4th- and 5th-year students recognized the presence or not of dental caries and selected the proper code for none or advanced caries, but they could not select the proper code for moderate caries. The 4th-year students and general practitioners suggested that follow up was the option treatment plan for initial dental caries. In contrast, 5th-year students suggested that surgical intervention (preparation) was the better option for early and moderate caries.

Uncompleted questionnaires were excluded from the ability score calculation. The completed questionnaires were from 176 respondents, as shown in Figure 1. There were significant differences among all groups in the ability to detect caries ( $P$-value: 0:00). The 4 th- and 5th-year students had the highest mean percentage ability score (53.8\% and $57.6 \%$, respectively) to detect caries using ICDAS compared to 3rd-year students and general practitioners $(38.6 \%$ and $38.7 \%$, respectively).

\section{Discussion}

The current study utilized eight clinical pictures to evaluate the ability of dentists and dental students to detect caries by using the ICDAS.

Overall, this study highlights the variation among participants in detecting dental caries by using the ICDAS code. More than half of the participants knew about ICDAS. This finding is attributed to the popularity of ICDAS internationally in scientific meetings or in published research due to its validity and reliability for detecting caries. ${ }^{17}$ However, participants could not recognize the proper ICDAS code especially for enamel caries (code \#1 and code \#2). This finding is in accordance with the studies by Zandona et $\mathrm{al}^{18}$ and El-Damanhoury et al ${ }^{19}$ which reported that the most difficult was code \#2. However, in the study by Zandona et al, there were no long-term effects in the theoretical or practical training that could be assessed to help students practice ICDAS with different cases in the long period.

All groups in the current study tended to under diagnose teeth as being without dental caries or limited to the enamel. Moreover, they did not select the proper ICDAS code. This is consistent with the study by Simões et $\mathrm{al}^{20}$ on Master's degree students; however, there was a small sample and few teeth used in that study, which was considered as the limitation for his study. A similar finding was by AlKhatrash et $\mathrm{al}^{21}$ regarding general practitioners and restorative dentists, which reported that the majority of the participants underdiagnosed caries that was limited to enamel.

Table 3 The Percentage of the Used System to Detect Dental Caries

\begin{tabular}{|l|c|c|c|c|c|}
\hline & \multicolumn{4}{|c|}{ Percentage\%(n) } \\
\hline System & $\begin{array}{c}\text { 3rd Year } \\
\text { Student }\end{array}$ & $\begin{array}{c}\text { 4th Year } \\
\text { Student }\end{array}$ & $\begin{array}{c}\text { 5th Year } \\
\text { Student }\end{array}$ & $\begin{array}{c}\text { General } \\
\text { Practitioner }\end{array}$ & Total \\
\hline $\begin{array}{l}\text { International Caries Detection and Assessment } \\
\text { System (ICDAS) }\end{array}$ & $11.7 \%(9)$ & $27.5 \%(19)$ & $37.5 \%(27)$ & $23 \%(23)$ & $24.5 \%(78)$ \\
\hline Other & $18.2 \%(14)$ & $29 \%(20)$ & $29.2 \%(21)$ & $18 \%(18)$ & $23 \%(73)$ \\
\hline I do not use any caries detection system & $70.2 \%(54)$ & $43.5 \%(30)$ & $33.3 \%(24)$ & $59 \%(59)$ & $52.5 \%(167)$ \\
\hline Total & $100 \%(77 / 77)$ & $100 \%(69 / 69)$ & $100 \%(72 / 72)$ & $100 \%(100)$ & $100 \%(318)$ \\
\hline
\end{tabular}




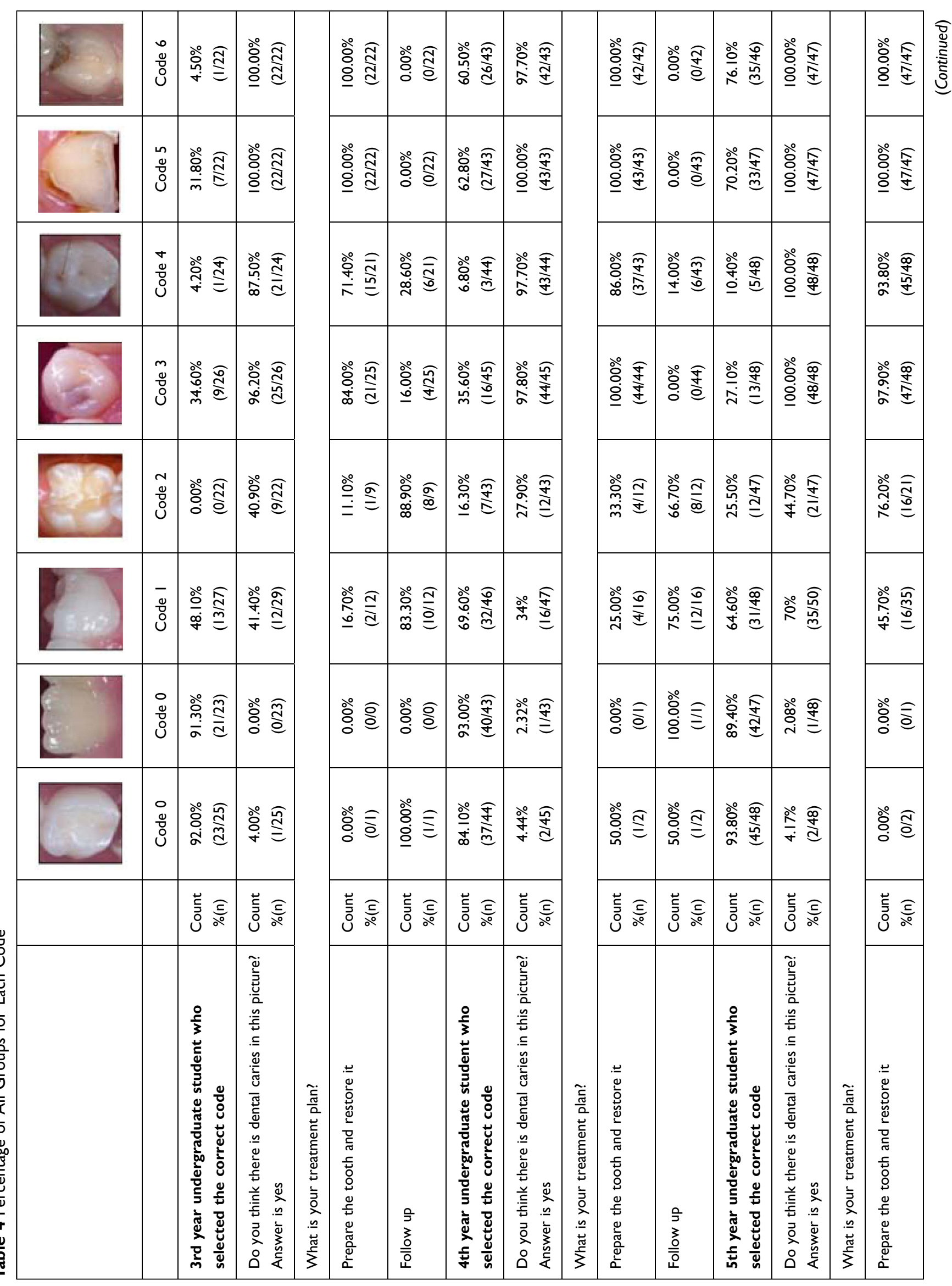




\begin{tabular}{|c|c|c|c|c|c|}
\hline ○̊ํㅇ & 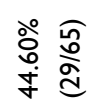 & $\begin{array}{l}\text { 웡 } \\
\text { 옹 } \\
\text { 응 }\end{array}$ & & 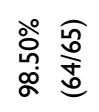 & 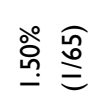 \\
\hline o̊ ㅇㅇㅇ & 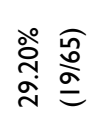 & $\begin{array}{l}\stackrel{\circ}{0} \\
\text { ○े } \\
\text { 을 }\end{array}$ & & 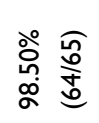 & 䱢 \\
\hline ○्तై & 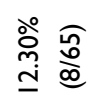 & 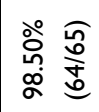 & & 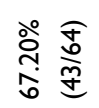 & 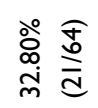 \\
\hline$\stackrel{\stackrel{\circ}{\mathrm{O}}}{\stackrel{\text { }}{=}}$ & 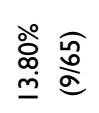 & 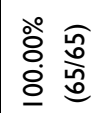 & & 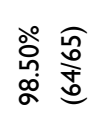 & 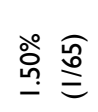 \\
\hline 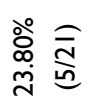 & 哭 令 & 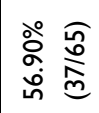 & & 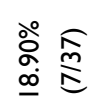 & $\begin{array}{l}\stackrel{\circ}{0} \\
\frac{\tilde{m}}{\infty} \\
\stackrel{\rho}{\rho}\end{array}$ \\
\hline 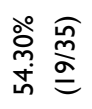 & 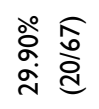 & $\begin{array}{ll}\stackrel{0}{0} \\
\text { in } \\
\text { in }\end{array}$ & & 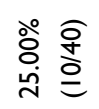 & 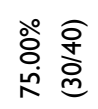 \\
\hline $\begin{array}{l}\stackrel{\circ}{\circ} \\
\text { ठ․ }\end{array}$ & 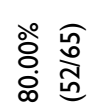 & $\frac{\stackrel{\circ}{\hat{\Sigma}}}{\stackrel{\widehat{m}}{\dot{m}}}$ & & ஃ̊ํㅇ & 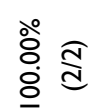 \\
\hline 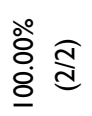 & 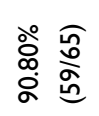 & ○ें & & 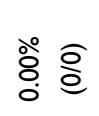 & $\stackrel{\circ}{\circ}$ 。ㅇ \\
\hline 䓂 ฏ & 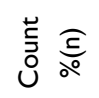 & 䓂 & & 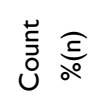 & $\stackrel{\breve{z}}{0} \widehat{\frac{c}{\circ}}$ \\
\hline $\begin{array}{l}\stackrel{9}{9} \\
z \\
\frac{0}{0} \\
\end{array}$ & 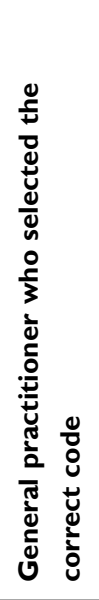 & 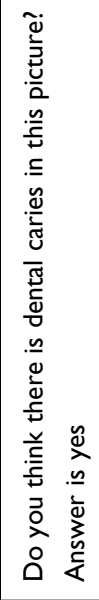 & 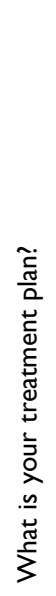 & 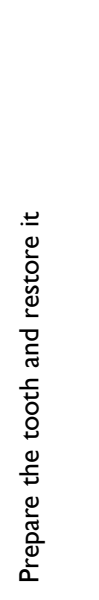 & $\begin{array}{l}0 \\
3 \\
z \\
\overline{0} \\
0\end{array}$ \\
\hline
\end{tabular}

Detecting early signs of caries that is limited to enamel is considered a challenge. ${ }^{19,22}$ This difficulty could be attributed to the fact that early lesions are symptomless, the variability in scientific knowledge and clinical training among dentists, and that there is no unique method to detect early caries lesions.

All participants need more training to improve their skills to utilize the ICDAS system properly. ${ }^{23}$ Therefore, combined scientific knowledge, clinical practice, and participating in e-learning programs many times for long periods of time will improve their caries diagnostic skills to apply the ICDAS system in the clinic. ${ }^{19,20,24,25}$

Faculty development training program on the ICDAS system has an effective impact on the learning of students, especially training to utilize evidence-based rationale of risk-based caries management. ${ }^{26}$ Therefore, teaching staff who is familiar with the ICDAS system usually encourage students to implement it in their clinic.

In the current study, all participants except for 5th-year students tended to follow up with early caries lesions because the new generation students are familiar with the concept of the remineralization process of early caries lesions. This finding supported the previous study, which reported that most students and dentists prefer the remineralization process and postpone surgical intervention until a definite cavity or radiolucency in dentin can be observed. ${ }^{26-28}$ In the current study, the general practitioners tended to be conservative in the management of early caries lesions, which was not consistent with a previous study ${ }^{21}$ that reported that general practitioners tended to over treat early caries, which could be attributed to the old dental education that they received. Many dental schools have moved toward teaching preventive strategies for caries management within the undergraduate curriculum to control the caries process. ${ }^{22,27,29}$

Encouraging dental students to conduct scientific research in ICDAS will prompt practice caries detection and management based on evidence. ${ }^{30}$ The current study highlights the variability in the ability of detecting caries among participants, which is consistent with a previous study. ${ }^{31}$

Moreover, the present study demonstrated that there were significant differences among all groups in their ability to detect caries, which differs from Zandona et al, which considers ICDAS as a new subject for participants. ${ }^{18}$ Other studies did not find a correlation between the experience of dentists and accurate diagnosis or conservative treatment options. ${ }^{21,32}$ The ability of the 3rd-year students to detect caries was low, which was in 


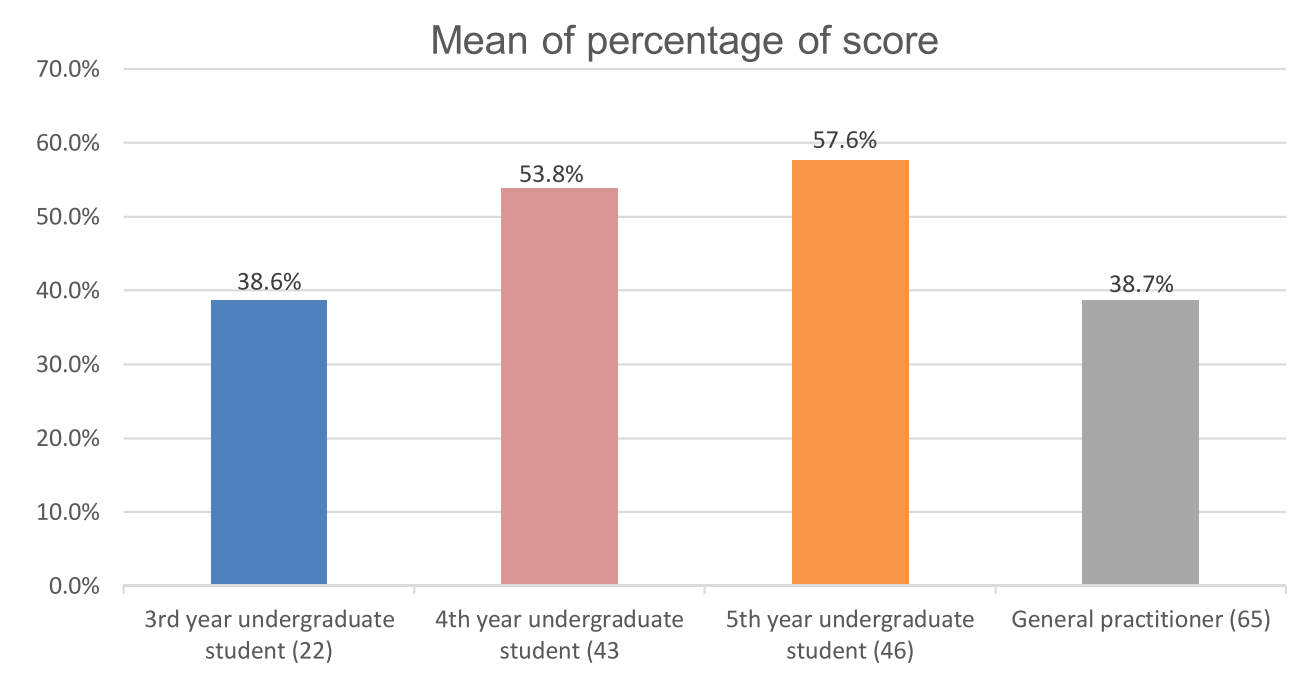

Figure I Mean of the percentage of ability score (8) to detect caries by using ICDAS for all groups, P value $(0.00)$.

contrast with Parviainen et $\mathrm{al}^{33}$ which reported that performance of their 3rd-year students was good. One possible explanation for this result is presence of training on ICDAS before the study, whereas in this study, participants did not receive training. The abilities of the 4th- and 5thyear students to detect caries were high. This finding could be attributed to the educational environment of students. They try to examine patients with attention and precision to achieve high accuracy of diagnosis and high grades from their supervisors. The ability of dentists and dental students to detect caries by using the ICDAS was low and needs improvement by further clinical training.

Even though many studies have confirmed the reliability and accuracy of ICDAS, ${ }^{34}$ few studies have discussed ICDAS and caries adjacent to restorations in addition to ICDAS and root caries, which are considered limitations of this system. ${ }^{34}$ Furthermore, it is difficult to use it with a non-cooperative child because achieving a dry tooth for examination is critical.

Some limitations of this study need to be considered when interpreting the results. Approximately half of the students could not complete the questionnaires, which could be attributed to their study load and stress of course requirements. ${ }^{35}$ Moreover, there was no specific time for diagnosis and selection of the proper code. Even though using a clinical picture in the current study was safe and avoided cross infection compared with a patient's mouth or extracted tooth, visual interpretation is variable due to quality of resolution, viewing angle, and distance from the monitor. Further study is needed to evaluate the ability of dentists and students to detect root caries and proximal caries in a radiographic film by using the ICDAS code.

\section{Conclusion}

Overall, there was variability in detecting dental caries among all groups in this study. Early dental caries limited to the enamel was confusing and difficult to detect. Most of the participants tended to rely on conservative management for early enamel caries rather than a surgical approach (preparation), especially new generation students.

\section{Acknowledgments}

The authors wish to thank the Institutional Review Board (IRB) at the King Saud University and Prof. Gail Douglas for her support. In addition, the authors would like to acknowledge and extend their gratitude to the ICDAS Foundation for providing them the opportunity to gain benefits from their experience. The authors also thank the general practitioners and students for their participation in this study.

\section{Funding}

No funding was considered.

\section{Disclosure}

The authors declare that there is no conflict of interest regarding the publication of this paper.

\section{References}

1. Pitts NB, Zero DT, Marsh PD, et al. Dental caries. Nat Rev Dis Prim. 2017;3:1-16. doi:10.1038/nrdp.2017.30

2. Vos T, Flaxman AD, Naghavi M, et al. Years lived with disability (YLDs) for 1160 sequelae of 289 diseases and injuries 1990-2010: a systematic analysis for the Global Burden of Disease Study 2010. Lancet. 2012;380(9859):2163-2196. doi:10.1016/S0140-6736(12) $61729-2$ 
3. Al Agili DE. A systematic review of population-based dental caries studies among children in Saudi Arabia. Saudi Dent J. 2013;25 (1):3-11. doi:10.1016/j.sdentj.2012.10.002

4. Wyne AH, Al-Ghorabi BM, Al-Asiri YA, Khan NB. Caries prevalence in Saudi primary schoolchildren of Riyadh and their teachers' oral health knowledge, attitude and practices. Saudi Med J. 2002;23 (1):77-81.

5. Alhabdan YA, Albeshr AG, Yenugadhati N, Jradi H. Prevalence of dental caries and associated factors among primary school children: a population-based cross-sectional study in Riyadh, Saudi Arabia. Environ Health Prev Med. 2018;23(1):1-14. doi:10.1186/s12199018-0750-z

6. Al-Rafee MA, Al Shammery AR, Al Rumikan AS, Pani SC. A comparison of dental caries in urban and rural children of the Riyadh region of Saudi Arabia. Front Public Heal. 2019;7:195. doi:10.3389/fpubh.2019.00195

7. Dikmen B. Icdas II criteria (international caries detection and assessment system). J Istanbul Univ Fac Dent. 2015;49(3):63. doi:10.17096/jiufd.38691

8. Gomez J. Detection and diagnosis of the early caries lesion. BMC Oral Health. 2015;15(1):S3. doi:10.1186/1472-6831-15-S1-S3

9. Sebastian TS, Johnson T. International caries detection and assessment system (ICDAS): an integrated approach. Int J Oral Heal Med Res. 2015;2(3):81-84.

10. Shivakumar K, Prasad S, Chandu G. International caries detection and assessment system: a new paradigm in detection of dental caries. J Conserv Dent. 2009;12(1):10. doi:10.4103/0972-0707.53335

11. Ekstrand K, Qvist V, Thylstrup A. Light microscope study of the effect of probing in occlusal surfaces. Caries Res. 1987;21 (4):368-374. doi:10.1159/000261041

12. Varma S, Banerjee A, Bartlett D. An in vivo investigation of associations between saliva properties, caries prevalence and potential lesion activity in an adult UK population. J Dent. 2008;36(4):294-299. doi:10.1016/J.JDENT.2008.01.009

13. Ismail AI, Sohn W, Tellez M, et al. The international caries detection and assessment system (ICDAS): an integrated system for measuring dental caries: methods. Community Dent Oral Epidemiol. 2007;35 (3):170-178. doi:10.1111/j.1600-0528.2007.00347.x

14. ICCMS. ICDAS international caries detection and assessment system. 2020. Available from: www.iccms-web.com/content/icdas. Accessed May 1, 2020.

15. Iruretagoyena MA. What is ICDAS? 2018. Available from: www. sdpt.net/ICDASEnglish.htm. Accessed April 11, 2020.

16. Pitts NB, Ismail AI, Martignon S, Ekstrand $\mathrm{K}$, Douglas GV, Longbottom C. ICCMS ${ }^{\mathrm{TM}}$ Guide for Practitioners and Educators. 2014.

17. Ekstrand K, Martignon S, Ricketts D, Qvist V. Detection and activity assessment of primary coronal caries lesions: a methodologic study. Oper Dent. 2007;32(3):225-235. doi:10.2341/06-63

18. Zandona AGF, Al-Shiha S, Eggertsson H, Eckert G. Student versus faculty performance using a new visual criteria for the detection of caries on occlusal surfaces: an in vitro examination with histological validation. Oper Dent. 2009;34(5):598-604. doi:10.2341/08-082-L

19. El-Damanhoury HM, Fakhruddin KS, Awad MA. Effectiveness of teaching international caries detection and assessment system II and its e-learning program to freshman dental students on occlusal caries detection. Eur J Dent. 2014;8(4):493-497. doi:10.4103/13057456.143631
20. Simões TC, Estevam M, Maciel SM, et al. Reliability of ICDAS to detect occlusal caries among Master's Degree students of Dentistry. $J \quad H e a l \quad$ Sci. 2019;21(2):115-120. doi:10.17921/24478938.2019v21n2p115-120

21. Al-Khatrash AA, Badran YM, Alomari QD. Factors affecting the detection and treatment of occlusal caries using the international caries detection and assessment system. Oper Dent. 2011;36 (6):597-607. doi:10.2341/10-346-L

22. Selwitz R, Ismail A, Pitts N. Dental caries. Lancet. 2007;369 (9555):51-59. doi:10.1016/S0140-6736(07)60031-2

23. Rodrigues JA, de Oliveira RS, Hug I, Neuhaus K, Lussi A. Performance of experienced dentists in Switzerland after an E-learning program on ICDAS occlusal caries detection. J Dent Educ. 2013;77(8):1086-1091. doi:10.1002/j.0022-0337.2013.77.8. tb05578.x

24. Luz PB, Stringhini CH, Otto BR, et al. Performance of undergraduate dental students on ICDAS clinical caries detection after different learning strategies. Eur $J$ Dent Educ. 2015;19(4):235-241. doi:10.1111/eje.12131

25. Diniz MB, Lima LM, Santos-Pinto L, Eckert GJ, Zandoná AGF, de Cássia Loiola Cordeiro R. Influence of the ICDAS E-learning program for occlusal caries detection on dental students. J Dent Educ. 2010;74(8):862-868. doi:10.1002/j.0022-0337.2010.74.8.tb04942.x

26. Pakdaman A, Evans RW, Howe E. Dental students' knowledge and perceptions of non-invasive dental caries management. Aust Dent J. 2010;55(1):28-36. doi:10.1111/j.1834-7819.2009.01183.x

27. Autio-Gold JT, Tomar SL. Dental students' opinions and knowledge about caries management and prevention. J Dent Educ. 2008;72 (1):26-32. doi:10.1002/j.0022-0337.2008.72.1.tb04449.x

28. Espelid I, Tveit AB, Mejàre I, Sundberg H, Hallonsten AL. Restorative treatment decisions on occlusal caries in Scandinavia. Acta Odontol Scand. 2001;59(1):21-27. doi:10.1080/000163501 300035724

29. Pitts NB, Mazevet ME, Mayne C, et al. Shaping the future of dental education: caries as a case-study. Eur J Dent Educ. 2018;22:30-37. doi:10.1111/eje. 12345

30. Al Sweleh F. Integrating scientific research into undergraduate curriculum: a new direction in dental education. J Heal Spec. 2016;4 (1):42. doi:10.4103/1658-600X.173845

31. Foley JI. Dental students consistency in applying the ICDAS system within paediatric dentistry. Eur Arch Paediatr Dent. 2012;13 (6):319-322. doi:10.1007/BF03320834

32. Swenson E, Hennessy B. Detection of occlusal carious lesions: an in vitro comparison of clinicians' diagnostic abilities at varying levels of experience. Gen Dent. 2009;57(1):60-66.

33. Parviainen H, Vähänikkilä H, Laitala ML, Tjäderhane L, Anttonen V. Evaluating performance of dental caries detection methods among third-year dental students. BMC Oral Health. 2013;13(1):1-8. doi:10.1186/1472-6831-13-70

34. Ekstrand KR, Gimenez T, Ferreira FR, Mendes FM, Braga MM. The international caries detection and assessment system - ICDAS: a systematic review. Caries Res. 2018;52(5):406-419. doi:10.1159/ 000486429

35. Al Sweleh F, Aldhili M, Alyami Y, Alotaibi M. Aggravating factor for course requirement stressor among dental students. Saudi J Heal Sci. 2017;6(2):96. doi:10.4103/SJHS.SJHS_79_16 


\section{Publish your work in this journal}

Clinical, Cosmetic and Investigational Dentistry is an international, peer-reviewed, open access, online journal focusing on the latest clinical and experimental research in dentistry with specific emphasis on cosmetic interventions. Innovative developments in dental materials, techniques and devices that improve outcomes and patient satisfaction and preference will be highlighted. The manuscript management system is completely online and includes a very quick and fair peer-review system, which is all easy to use. Visit http://www.dovepress.com/testimonials.php to read real quotes from published authors.

Submit your manuscript here: https://www.dovepress.com/clinical-cosmetic-and-investigational-dentistry-journal 